\title{
BEWOORDINGEN VAN DE GOEDKEURENDE ACCOUNTANTSVERKLARINGEN BIJ VERANTWOORDINGEN
}

\author{
door H. Baas
}

\section{Inleiding}

In artikel 14 lid 4 GBR is bepaald, dat een stuk, dat is afgegeven door of namens een registeraccountant en dat een niet door of mede door hem afgelegde verantwoording bevat, geacht wordt een goedkeurende verklaring zonder voorbehoud in te houden tenzij het tegendeel blijkt door gebruik van één der in het eerste tot en met derde lid van dat artikel en in artikel 6 voorgeschreven bewoordingen. Door deze opbouw is het niet nodig, dat de GBR voorschriften bevat omtrent de te gebruiken bewoordingen van de goedkeurende verkla. ring.

In de vakliteratuur worden aan de formulering van de verklaring doorgaans drie eisen gesteld, t.w. duidelijkheid, volkomenheid en beknoptheid. Algemeen werd en wordt erkend, dat een uniforme tekst het meest aan deze eisen be. antwoordt. Dit was in 1972 voor het NIVRA aanleiding om het gebruik van een door haar ontworpen uniforme tekst voor de goedkeurende verklaringen bij jaarrekeningen aan te bevelen.

Naast jaarrekeningen bestaan er echter nog andere verantwoordingen, waarover aan accountants wordt verzocht hun oordeel uit te spreken. De voordelen van de uniforme tekst van de verklaring bij een jaarrekening pleiten ook voor een uniforme tekst bij deze andere verantwoordingen.

Op de najaarsconferentie 1979 van het NIVRA handelende over actuele vraagstukken rond de beroepsregels stond o.a. bovengenoemd onderwerp op de agenda. Bij de congresstukken behoorde onder meer een door de CTB voorbereid voorstel voor een ontwerp-meningsuiting. Hierin worden voor een aantal veel voorkomende verantwoordingen standaardteksten van goedkeu. rende accountantsverklaringen aanbevolen, waarbij de standaardtekst van de goedkeurende verklaring bij jaarrekeningen als uitgangspunt is genomen.

De aanbevolen teksten zijn: 
1.1. Jaarrekeningen van de in art. 306 Boek 2 B.W. genoemde rechtspersonen.

1.2. Jaarrekeningen van de niet in art. 306 Boek 2 B.W. genoemde rechtspersonen, die evenwel voldoen aan de in titel 6 Boek 2 B.W. genoemde minimum-eisen van presentatie en inzicht.
1. Wij hebben de jaarrekening $19 \ldots$ van de N.V. gecontro. leerd. Op grond van ons onder. zoek zijn wij van oordeel, dat deze jaarrekening een getrouw beeld geeft van de grootte en sa. menstelling van het vermogen van de vennootschap op ... 19 ... en van het resultaat over $19 \ldots$
2.1. Jaarrekeningen van de niet in art. 306 Boek 2 B.W. genoemde rechtspersonen, die (nog) niet voldoen aan de in titel 6 Boek 2 B.W. genoemde minimum ei. sen van presentatie en inzicht, doch overigens wel aan de eraan te stellen eisen voldoen.

2.2. Jaarrekeningen, waarvan niet vereist is, dat zij inzicht geven in vermogen en/of resultaten, doch qua presentatie en toelich. ting wel een getrouw beeld ge. ven van de uitkomsten van het gevoerde financiële beheer.
2. Wij hebben de jaarrekening ge. controleerd. Op grond van dit onderzoek zijn wij van oordeel, dat deze verantwoording een ge. trouw beeld geeft van de uitkomsten van het over $19 \ldots$ ge voerde financiële beheer. 
B. Andere verantwoordingen dan jaarrekeningen

3. Verantwoordingen op jaarrekeningen gelijkend, die niet voldoen aan de normen van presentatie en inzicht vastgelegd in titel 6 Boek 2 B.W.

3. Wij hebben de... over $19 \ldots$ van ... gecontroleerd. Deze... is bestemd voor... Op grond van dit onderzoek zijn wij van oordeel, dat deze . . . voldoet aan de voor dit doel daaraan te stel. len eisen.

4. Verantwoordingen op jaarrekeningen gelijkend, die wel voldoen aan de normen van pre. sentatie en inzicht vastgelegd in titel 6 Boek 2 B.W.

4. Wij hebben de... over $19 \ldots$ van... gecontroleerd. Deze is bestemd voor ... Op grond van dit onderzoek zijn wij van oor. deel dat deze... voldoet aan de voor dit doel daaraan te stel. len eisen en een getrouw beeld geeft van de grootte en samenstelling van het vermogen van de . . op . . 19 . . en van het resultaat over...

5. Balans met toelichting grote b.v.

5. Wij hebben de jaarrekening 19 . . van ... gecontroleerd. Op grond van dit onderzoek zijn wij van oordeel, dat de balans met toelichting een getrouw beeld geeft van de grootte en samen. stelling van het vermogen van de vennootschap op ...19 . .

6. Andere verantwoordingen niet

6. Geen aanbevolen tekst. op jaarrekeningen gelijkend

In het volgende hoofdstuk zullen deze standaardteksten worden besproken, waarna in hoofdstuk 3 zal worden nagegaan of en zo ja welke alternatieven er mogelijk zijn. De bereikte conclusies zijn ter afsluiting in hoofdstuk 4 opgenomen. 


\section{Kritische beoordeling van de door de CTB aanbevolen standaardteksten}

Een aantal van de hierna uiteengezette bezwaren komen overeen met die van een aantal collega's tegen een door de CTB in 1972 aanbevolen standaard. tekst. (Zie NIVRA·berichten juni 1972.)

\subsection{Standaardtekst 1}

a. Het is niet raadzaam dat in de tekst aansluiting is gezocht met het bepaalde in art. 308 boek 2 B.W. Een jaarrekening van een vennootschap, waarop titel 6 boek 2 B.W. van toepassing is, moet volkomen aan de bepalingen van de wet voldoen.

Door het gebruik in de accountantsverklaring bij de jaarrekening van be woordingen, die in een bepaald artikel van de wet zijn opgenomen, kan bij de onbevangen beschouwer de vraag opkomen of de accountant nu ja dan neen heeft gecontroleerd of de jaarrekening ook aan andere wettelijke eisen voldoet.

b. Indien men een bepaalde standaardtekst uitsluitend van toepassing verklaart op jaarrekeningen, die verplicht dan wel niet verplicht voldoen aan de wettelijke bepalingen zoals opgenomen in titel 6 boek 2 B.W. lijkt het duidelijker om er in de standaardtekst melding van te maken, dat de jaar rekening aan de wettelijke bepalingen voldoet. Deze verwijzing is evenwel niet in de tekst van de verklaring opgenomen.

c. Deze standaardtekst wordt ook aanbevolen voor jaarrekeningen van huishoudingen die weliswaar niet hiertoe verplicht, voldoen aan de bepalingen van titel 6 boek 2 B.W. Indien een dergelijke jaarrekening evenwel niet aan de wettelijke bepalingen voldoet, behoeft dit niet in de verklaring te wor. den vermeld, doch zal indien de verantwoording toch voldoet aan de eraan te stellen eisen verklaring nr. 2 worden afgegeven.

Gevreesd moet worden, dat indien gebruikers van verklaringen in een con creet geval jaarrekeningen onder ogen krijgen van ondernemingen etc., die niet zijn onderworpen aan de bepalingen van titel 6 boek $2 \mathrm{~B}$.W. waarbij in het ene geval een verklaring nr. 1 en in het andere geval verklaring nr. 2 is afgegeven, òf het verschil voor hen niet duidelijk zal zijn òf zij geneigd zullen zijn aan een verantwoording met een verklaring nr. 1 meer vertrouwen te hechten dan aan een jaarrekening vergezeld van verklaring nr. 2.

d. Het is niet zonder meer duidelijk, wat het begrip vermogen in de tekst inhoudt. Het ligt voor de hand, dat hiermede het totale vermogen (eigen en vreemd vermogen op lange en op korte termijn) wordt bedoeld. De vraag kan dan wel worden gesteld, waarom niets wordt verklaard omtrent de ac. tiefzijde (het kapitaal), waarin de huishouding het vermogen heeft opgesloten.

e. Het is algemeen gebruikelijk en voor vennootschappen, die onderworpen zijn aan de bepalingen van titel 6 boek 2 B.W. zelfs verplicht, dat in de jaarrekening tevens de overeenkomstige cijfers van het voorgaande jaar zijn opgenomen. Omtrent de verklaring, die destijds bij de overeenkomstige cijfers is afgegeven, geeft deze standaardtekst ten onrechte geen uitsluitsel. Echter, iedere accountant zal, indien bij de overeenkomstige cijfers destijds een andere dan een ,schone” goedkeurende verklaring was afgegeven, dit 
feit in zijn verklaring bij de volgende jaarrekening vermelden.

Het lijkt ons daarom beter om in navolging van hetgeen hieromtrent b.v. in de U.S.A. is voorgeschreven in de verklaring te allen tijde de opgenomen overeenkomstige cijfers over het voorgaande jaar te betrekken.

f. De term ,getrouw beeld geeft van de grootte en samenstelling van het re. sultaat" laat onvoldoende uitkomen, dat dit beeld mede afhankelijk is van de bij het opmaken van de jaarrekening toegepaste waarderings- en winstbepalingsgrondslagen. De term wordt b.v. zowel gebruikt bij jaarrekeningen gebaseerd op historische prijzen als bij die gebaseerd op actuele waarde. In een standaardtekst in deze vorm wordt daarom een verwijzing naar de toegepaste waarderings- en winstbepalingsgrondslagen node gemist. De discussie hierover is reeds oud, doch zal indien men deze standaardtekst blijft toepassen, vermoedelijk niet tot een einde komen.

\subsection{Standaardtekst 2}

Een aantal van de onder 2.1 genoemde bezwaren zijn ook op deze standaard. tekst van toepassing, te weten, die genoemd onder c. en e. Naast deze bezwa. ren kunnen tegen deze standaardtekst nog andere worden aangevoerd, te weten:

g. Deze tekst kan gemakkelijk verkeerd worden geïnterpreteerd. De leek kan namelijk de indruk krijgen, dat de accountant niet alleen een goedkeurend oordeel uitspreekt over de uitkomsten van het gevoerde financiële beheer, doch tevens over het beheer zelf, hetgeen bepaald niet door hem wordt bedoeld. Met name in het theoretisch denkbare geval, dat een goedkeurende verklaring volgens deze tekst wordt afgegeven bij een verantwoor. ding van een verantwoordingsplichtige, waarbij in meerdere of mindere mate sprake is van wanbeheer, zou dat een kwalijke uitleg van de tekst zijn, die men door het kiezen van andere bewoordingen eenvoudig kan voorkomen.

h. Onze volgende kritiek richt zich op het woord „beheer”. In ons vakjargon komen wij dit woord in twee betekenissen tegen, namelijk enerzijds in de aan een organisatie te stellen eis van functiescheidingen tussen personen belast met het beheren, het bewaren en het registreren. Hier heeft het de betekenis van beschikken, waaronder volgens Starreveld moet worden verstaan zowel het geven van opdrachten en machtigingen en het aangaan van verplichtingen als het geven van kwijtingen. Anderzijds komen wij in ons vakjargon dit woord tegen in termen als kasbeheer, voorraad. beheer etc. Hier heeft het de betekenis van bewaren.

Wij nemen aan, dat onder het woord "beheer" in de standaardtekst moet worden verstaan ,beleid”.

Het zou duidelijker geweest zijn, indien men dan ook maar voor dit woord had gekozen in plaats van het voor meerdere uitleg vatbare woord „beheer".

i. De tekst wekt ten onrechte de indruk, dat de jaarrekening uitsluitend de resultaten aangeeft van het „financiële beheer" (in de betekenis van beleid). Het financiële beleid is echter een onderdeel van het totale beleid net zoals inkoop-, verkoop- en personeelsbeleid hiervan deel kunnen uitmaken. De financiële uitkomsten van dit totale beleid behoren in de jaarrekening tot 
uitdrukking te komen. Deze standaardtekst maakt dit onvoldoende duidelijk.

\subsection{Standaardtekst 3}

Het hiervan onder e. genoemde bezwaar is ook op deze tekst van toepassing. Hieraan kan nog het volgende worden toegevoegd.

$j$. Een verantwoording moet volkomen voor zich spreken.

Dat betekent, dat indien er sprake is van een verantwoording, waarvan de doelstelling niet wettelijk is bepaald, dan wel, niet algemeen bekend mag worden verondersteld, deze in de verantwoording moet worden vermeld. Indien de doelstelling in de verantwoording is vermeld, is het vanzelfsprekend onnodig, zoals in deze tekst aanbevolen, deze tevens in de accoun tantsverklaring op te nemen.

Indien nu het geval zich voordoet, dat de accountantsverklaring wordt afgegeven bij een verantwoording, waarvan de doelstelling niet wettelijk is bepaald of algemeen bekend is en deze niet expliciet in de verantwoording is vermeld, vertoont de verantwoording onvolkomenheden en voldoet dientengevolge niet aan de daaraan te stellen eisen. Deze onvolkomenheid kan nimmer worden goedgemaakt door de doelstelling in de accountantsverklaring op te nemen.

\subsection{Standaardtekst 4}

Buiten de onder e., b. en j. opgenomen bezwaren, die ook op deze tekst van toepassing zijn, is op deze verklaring nog het volgende aan te merken.

$k$. De standaardtekst wordt aanbevolen voor verantwoordingen op jaarrekeningen gelijkend, die hoewel niet verplicht, toch voldoen aan de normen van presentatie en inzicht, vastgelegd in titel 6 , boek 2 B.W. Op grond hiervan worden de verklaringen nr. 1 en nr. 3 gecombineerd tot één verklaring. Dit lijkt ons een beetje dubbel op. Men mag er van uitgaan, dat de hier bedoelde verantwoording niet ,per ongeluk" aan de bepalingen van titel 6 boek 2 B.W. voldoet, maar dat dit één van de eisen is geweest, waar aan de verantwoording dient te voldoen. Er van uitgaande, dat er hier. naast meerdere eisen zijn geweest, waarmede bij het samenstellen van de verantwoording rekening moest worden gehouden, zien wij niet in, waar. om in de accountantsverklaring bij een dergelijke verantwoording naast het feit, dat de verantwoording voldoet aan de eraan te stellen eisen, der halve alle eisen, inclusief die van het voldoen aan het bepaalde in titel 6 boek 2 B.W. nog moet worden vermeld, dat deze tevens een getrouw beeld geeft van grootte en samenstelling van vermogen en resultaat, daar dit reeds impliciet is verklaard. Het laatste gedeelte van de tekst is daarom reeds begrepen in het eerste gedeelte. Deze tekst voldoet derhalve niet aan de eis van beknoptheid.

\subsection{Standaardtekst 5}

Op deze tekst zijn de bezwaren genoemd onder a., b., d., e. en f. eveneens van toepassing. Daarnaast is nog de volgende aantekening te maken.

$l$. In de tweede zin van de verklaring is ten onrechte niet aangegeven, dat de balans met toelichting, waarbij de verklaring wordt gegeven, deel uit- 
maakt van de jaarrekening van de in de eerste zin van de standaardtekst bedoelde grote besloten vennootschap.

\section{Alternatief van de door de CTB aanbevolen standaardtekst}

In hoofdstuk 1 is reeds gesteld aan welke eisen de accountantsverklaring moet voldoen, t.w. duidelijkheid, volkomenheid en beknoptheid. Toen de door Lim. perg op grond van deze eisen voorgestelde enkele handtekening weinig of geen navolging vond, ging iedere accountant dan wel maatschap zijn eigen verklaring ontwerpen. De gewenste duidelijkheid werd hierdoor vanzelfsprekend niet bereikt. Dit was voor het NIVRA aanleiding om in 1972 één standaardtekst aan te bevelen. Het is niet geheel duidelijk of deze standaardtekst uitsluitend werd aanbevolen voor jaarrekeningen van lichamen, die onder. worpen waren aan de bepalingen van de $\mathrm{WJO}$ (titel 6 boek $2 \mathrm{~B} . \mathrm{W}$.). Wel is zeker, dat ook bij andere instellingen gebruik van deze verklaring wordt gemaakt. Uitgaande van de eis van duidelijkheid, geïnterpreteerd vanuit de gebruikers zijn hiervoor ook wel enige argumenten aan te voeren. Dezelfde ar. gumenten, echter nu bezien vanuit het accountantsstandpunt hebben geleid tot de besproken uitbreiding van het aantal standaardteksten voor goedkeu. rende accountantsverklaringen van 1 tot 5 , waarbij iedere tekst bij een bepaald soort verantwoording behoort.

Echter door middel van vijf verschillende antwoorden op steeds dezelfde aan de accountant gestelde vraag, te weten voldoet de verantwoording aan de eraan te stellen eisen, waarbij dan de formulering van het antwoord afhangt van het soort verantwoording, kan men nooit de vereiste duidelijkheid bereiken. Daarom is deze voorgestelde uitbreiding van het aantal standaardteksten eerder een stap terug naar de vroegere onduidelijke situatie dan een stap voor. waarts naar de beoogde duidelijkheid.

Onze GBR bepalen in art. 1, dat een verklaring is een schriftelijke medede. ling van een accountant inhoudende de uitkomst van een onderzoek naar de getrouwheid van een verantwoording. Volgens art. 13 lid 1 houdt een goedkeurende verklaring in, dat de verantwoording voldoet aan de eraan te stellen eisen. Waaruit deze eisen bestaan, geven de GBR niet aan en kunnen ze ook niet aangeven, aangezien deze afhankelijk zijn van het soort verantwoording en het doel ervan. Alleen voor een jaarrekening of bescheiden, die bij andere huishoudingen dan ondernemingen daarvoor in de plaats treden, wordt een uitzondering gemaakt. Art. 17 lid 2 bepaalt namelijk, dat een goedkeurende verklaring bij een verantwoording het oordeel inhoudt, dat deze een zodanig inzicht geeft in de grootte en samenstelling van het vermogen en resultaat van de huishouding, als in de gegeven omstandigheden vereist is.

Volgens de toelichting op het ontwerp.GBR dient onder een verantwoor. ding te worden verstaan: „Elke kwantitatieve voorstelling van feitelijkheden voor zover daaraan een verantwoordingskarakter moet worden toegekend" en onder een jaarrekening het stuk, dat dient als c.q. de functie heeft van de uiteindelijke beheersverantwoording van de leiding aan het bevoegde orgaan.

Tijdens de behandeling van de ontwerp.GBR is er over artikel 17 uitvoerig gediscussieerd, met name over het laatste gedeelte van het eerste lid. De conclusie van deze discussie was, dat jaarrekeningen zoals hiervoor gedefinieerd 
moeten bestaan uit een balans, een winst. en verliesrekening en een toelichting en dat een jaarrekening inzicht moet geven in grootte en samenstelling van vermogen en resultaat. Dit zou dan betekenen, dat in afwijking van de toelichting bij de ontwerp-GBR een staat van inkomsten en uitgaven van een overheidsorgaan niet een stuk is, dat onder artikel $17 \mathrm{GBR}$ valt, daar in een dergelijke verantwoording geen inzicht in vermogen en resultaat wordt gebo. den. Daarentegen dient echter een dergelijk stuk wel als een uiteindelijke be. heersverantwoording te worden gezien, waardoor het wel weer onder de definitie van jaarrekening valt. In de ontwerp-meningsuiting op pag. 2 staat vermeld, dat een jaarrekening niet onder alle omtandigheden inzicht geeft in samenstelling en grootte van vermogen en resultaat. Al met al blijkt het nog niet zo eenvoudig te zijn om vast te stellen wat men onder een jaarrekening dient te verstaan. Het lijkt goed om te overwegen om art. 17 GBR te laten vervallen. Met artikel 13 lid I GBR, waarin is bepaald, dat de goedkeurende verklaring inhoudt, dat de accountant tot het oordeel gekomen is, dat de verantwoording voldoet aan de eraan te stellen eisen, kan het beroep volstaan.

Dit nog te meer, daar, zoals wij in het voorgaande hebben betoogd, uit de verantwoording zelf de doelstelling ervan dient te blijken. Bij de ene verant. woording zal dit zijn het geven van inzicht in grootte en samenstelling van het vermogen van de verantwoordingsplichtige, bij een andere verantwoording daarentegen het verstrekken van een overzicht van de ontvangsten en uitgaven etc. De doelstelling is een gegeven voor de accountant. Hij heeft hierop geen directe invloed, doch heeft slechts als taak vast te stellen of de verantwoording al dan niet aan deze doelstelling beantwoordt of anders gezegd of deze al dan niet voldoet aan de eraan te stellen eisen.

Met betrekking tot aan een verantwoording te stellen eisen dient onder. scheid te worden gemaakt tussen twee aspecten hiervan, te weten het juistheids- en het toereikendheidsaspect. Het eerstgenoemde heeft betrekking op cijfermatige juistheid van de verantwoording.

Het toereikendheidsaspect doelt op de bij het opmaken van de verantwoor ding gehanteerde grondslagen, waarvan de keuze overigens afhankelijk is van het doel van de verantwoording.

Deze aspecten, waarop de accountant ook zijn controle richt, zijn bij alle soorten verantwoordingen te onderscheiden. Het lijkt daarom voor de hand te lig. gen om in de verklaring naar deze aspecten te verwijzen.

Op grond van het voorgaande willen wij de volgende standaardtekst voor de goedkeurende accountantsverklaring aanbevelen:

„Wij hebben de ... (naam van de verantwoording) van . . (naam van de verantwoordingsplichtige) over/per ... (jaar/datum) (eventueel jaren en data) aan een onderzoek naar de getrouwheid onderworpen.

Wij zijn van oordeel, dat deze voor wat juistheid en toereikendheid betreft, voldoet (voldoen) aan de daaraan te stellen eisen').

Hierbij willen wij nog de volgende toelichting geven:

- De tekst is bij iedere verantwoording toe te passen. In plaats van vijf wordt

\footnotetext{
I) Deze tekst komt gedeeltelijk overeen met de door Prof. A. B. Frielink aanbevolen standaardtekst zoals deze is opge nomen in NIVRA-berichten juni 1972.
} 
het aantal goedkeurende accountantsverklaringen teruggebracht tot één, hetgeen de duidelijkheid bevordert.

- Door in de eerste zin aan te sluiten bij de terminologie van art. 1 GBR kan er geen misverstand over bestaan, dat in de tweede zin een accountantsverklaring wordt gegeven.

- Volgens art. 13 lid 1 GBR houdt een goedkeurende verklaring in, dat de registeraccountant tot het oordeel is gekomen, dat de verantwoording voldoet aan de eraan te stellen eisen. Door in de aanbevolen standaardtekst zoveel mogelijk de in dit artikel gebezigde bewoordingen te gebruiken, is ieder misverstand over de strekking van de verklaring onmogelijk.

- De gebruikers van de verklaring dienen op de hoogte te zijn van de aan de verantwoording te stellen eisen. Indien deze eisen in wetten zijn vastgelegd of bij de gebruikers van de verklaring uit andere hoofde voldoende bekend zijn, kan hierover geen misverstand bestaan. In andere gevallen zal de accountant echter zijn verklaring slechts mogen geven indien in de verantwoording de eraan te stellen eisen expliciet zijn opgenomen. Dit is het aspect van de toereikendheid, dat in de aanbevolen tekst opgenomen is.

- Door in de standaardtekst onderscheid te maken tussen de aan de verant. woording te stellen eisen voor wat betreft juistheid en toereikendheid wordt het mogelijk om in de gevallen, waarin de accountant geen goedkeurende verklaring kan geven in zijn verklaring aan te geven of de aan. leiding hiervan is gelegen in onzekerheden en/of bedenkingen met betrekking tot de juistheid en/of de toereikendheid van de verantwoording. Aldus zal het wellicht ook mogelijk worden om in de verklaring van oordeelonthouding, waartegen wij overigens grote bezwaren hebben, enige nuanceringen aan te brengen, waardoor een einde kan worden gemaakt aan de negatieve interpretatie van deze verklaring.

- Door in de standaardtekst, mits opgenomen, tevens naar de overeenkom. stige cijfers van de voorgaande periode te verwijzen, sluit men aan bij de voorschriften, die dienaangaande in de Verenigde Staten gelden, hetgeen de uniformiteit bevordert.

- De consequenties van deze aanbevolen standaardtekst van de goedkeurende verklaring voor de overige mogelijke verklaringen zijn hier niet verder uitgewerkt. In de concept-meningsuiting van de CTB heeft dit overigens ook niet plaatsgehad. Het spreekt vanzelf, dat welke van de aanbevolen verklaringen ook zullen worden aanvaard, de gevolgen voor met name art. 14 GBR nader moeten worden aangegeven.

- Met de door ons aanbevolen standaardtekst kan men internationaal niet dan wel nauwelijks uit de voeten. Overigens geldt dit ook voor de huidige aanbevolen standaardtekst en de door de CTB aanbevolen teksten. Art. 14 lid 4 GBR, laatste gedeelte spreekt niet over een vertaling van bewoordin. gen uit de GBR in een vreemde taal, doch over het gebruik van een equivalent daarvan in de taal, waarin de verklaring is gesteld. Dit geldt ook voor de standaardtekst voor de goedkeurende verklaring. Dit heeft dan als consequentie, dat indien sprake is van b.v. een Amerikaanse of Engelse ver. klaring het voor de hand ligt om in de verklaring zoveel mogelijk aansluiting te zoeken met de in die landen gebruikte uniforme teksten. 


\section{Conclusie}

Uit het voorgaande kan worden geconcludeerd, dat naar onze mening de door de CTB aanbevolen vijf standaardteksten voor goedkeurende accountantsver. klaringen bij verantwoordingen dienen te worden vervangen door één nieuwe tekst, die bij alle mogelijke verantwoordingen kan worden toegepast.

Aldus wordt voldaan aan de aan de verklaring te stellen eisen voor wat betreft duidelijkheid, volkomenheid en beknoptheid. 